\title{
Updated Survival Analysis after a Median Follow-up of 12 Years of an Anthracycline-Containing Adjuvant Prospective Multicentre, Randomised Phase III Trial on Dose-Dense Chemotherapy in Primary Node-Positive, High-Risk Breast Cancer Patients
}

\author{
Mattea Reinisch ${ }^{a}$ Oleg Gluz ${ }^{\mathrm{b}}$ Beyhan Ataseven ${ }^{\mathrm{c}}$ Jens-Uwe Blohmer ${ }^{\mathrm{d}}$ Marek Budner \\ Christine Dittmer-Grabowski ${ }^{a}$ Andreas Kohls ${ }^{f}$ Jutta Krocker ${ }^{g}$ Aylin Kümmel ${ }^{a}$ \\ Friederike Hagemann $^{\text {a }}$ Anna Rüland ${ }^{\mathrm{a}}$ Alexander Traut ${ }^{\mathrm{h}}$ Sherko Kümmel ${ }^{\mathrm{a}}$ \\ ${ }^{a}$ Breast Unit, Evangelische Huyssens-Stiftung, Kliniken Essen Mitte, Essen, Germany;

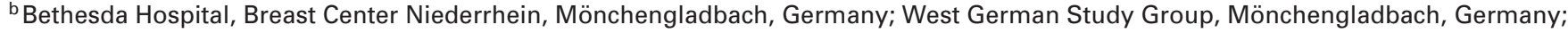 \\ ${ }^{\mathrm{c}}$ Department of Gynecology and Gynecologic Oncology, Evangelische Huyssens-Stiftung, Kliniken Essen-Mitte, Essen, Germany; \\ ${ }^{\mathrm{d} B r e a s t}$ Center, Charité Hospital Berlin, Berlin, Germany; \\ ${ }^{\text {e } B r e a s t ~ U n i t, ~ H e l i o s ~ K l i n i k u m, ~ B a d ~ S a a r o w, ~ G e r m a n y ; ~}$ \\ ${ }^{f}$ Breast Unit, Evangelisches Krankenhaus Ludwigsfelde-Teltow, Ludwigsfelde-Teltow, Germany; \\ gBreast Unit, Sana Klinikum Berlin-Lichtenberg, Berlin, Germany; \\ h Statistician, Kliniken Essen-Mitte, Essen, Germany
}

\section{Keywords}

Adjuvant dose-dense chemotherapy .

Node-positive early breast cancer - Long-term follow-up . Disease-free survival · Overall survival

\section{Summary}

Purpose: Although dose-dense (dd) chemotherapy plays a fundamental role in the treatment of breast cancer $(\mathrm{BC})$, a variety of trials have presented divergent survival results. Here, we present data of patients with more than 3 positive axillary lymph nodes $(+a L N)$ receiving $d d$ chemotherapy after a median follow-up period of 12.3 years. Methods: In the years 1996-2000, 231 patients with invasive $\mathrm{BC}, \geq \mathrm{pN2a}$ and no evidence of distant metastases were recruited to receive treatment $A$, i.e. dd $3 \times$ epirubicin $\left(E, 90 \mathrm{mg} / \mathrm{m}^{2}\right)+$ paclitaxel $\left(P, 175 \mathrm{mg} / \mathrm{m}^{2}\right)$ every 2 weeks (q2w) followed by $3 \times$ cyclophosphamide (C)/methotrexate/5-fluorouracil (CMF, 600/40/600 mg/m², $\mathrm{q} 2 \mathrm{w})$, or treatment B, i.e. $4 \times E+C\left(C, 600 \mathrm{mg} / \mathrm{m}^{2}\right) \mathrm{q} 3 \mathrm{w}$ followed by $3 \times$ CMF q3w. Results: 113 patients in arm $A$ and 113 patients in arm $B$ were analysed after an updated median follow-up of 12.3 years. The median age was 55 years, with a median number of $6+a L N, 50.4 \%$ had a T2 and $79.2 \%$ hormone receptor-positive BC. The disease-free survival (DFS) rate was $53.1 \%$ in arm $A$ and $42.5 \%$ in arm $B$ (adjusted $p=0.027$ ). The overall survival (OS) rate was $54.9 \%$ in arm $A$ and $48.7 \%$ in arm B (adjusted $p=0.058)$. In the multivariable analysis, the tumour burden was a significant predictor for DFS and OS. Conclusion: The adjuvant use of dd chemotherapy led to a statistically significant improvement of DFS after a follow-up of 12.3 years.

(C) 2018 S. Karger AG, Basel

\section{Introduction}

Adjuvant chemotherapy in patients with early breast cancer and high risk of relapse significantly improves the patient's outcome [1, 2]. However, whether the administration of chemotherapy adds more benefit when given biweekly (dose dense) or 3-weekly has remained controversial. Studies investigating this aspect have published diverse results. Some phase III trials demonstrated an improved disease-free survival (DFS) and overall survival (OS) especially in patients with high tumour burden [3-7], whereas other studies failed to prove this advantage [8-11].

\section{KARGER}

() 2018 S. Karger AG, Basel 
The initial trial demonstrating a significant OS benefit was the Cancer and Leukemia Group B (CALGB) trial 9741 [3] with a 4 -year DFS rate of $82 \%$ for the dose-dense regimens versus $75 \%$ for the standard-dose regimens and confirmed an improved outcome for the dose-dense chemotherapy after a follow-up period of 12 years (hazard ratio (HR) 1.20, 95\% confidence interval (CI) $0.99-$ 1.44) [12].

The TECHNO trial [4] and the GIM-II trial [6] confirmed the improvement of dose-dense regimens thereafter. Patients received epirubicin/paclitaxel (EP) every 2 weeks ( $\mathrm{q} 2 \mathrm{w}$ ) compared to every 3 weeks (q3w), followed by cyclophosphamide/methotrexate/5fluorouracil (CMF) in the TECHNO study. A median DFS rate of $70 \%$ was found for the $\mathrm{q} 2 \mathrm{w}$ group versus $59 \%$ for the standard $\mathrm{q} 3 \mathrm{w}$ group ( $\mathrm{p}=0.011$ ), and an OS rate of $83 \%$ versus $77 \%$, respectively $(\mathrm{p}=0.41)$. The GIM-II trial supports the superiority of the dosedense regimes. After 5 years of follow-up, the DFS and OS rates were significantly better for patients receiving epirubicin/cyclophosphamide-paclitaxel (EC-P) every 2 weeks compared to every 3 weeks.

However, the phase III GONO-MIC trial [11], the UK TACT trial [13] and the Panther trial [9] did not demonstrate superiority of dose-dense or dose-intense chemotherapy regimens over standard regimens. Reasons for this difference have been discussed extensively [14-16]. Differences in the patients' risk profiles with inhomogeneous amounts of positive axillary lymph nodes have been considered as one possible explanation for inconsistent results.

Therefore, the depth of the impact of the dose-dense or doseintense chemotherapy remains controversial. Nevertheless, based on the results of a variety of meta-analyses $[15,17]$, the benefit of a dose-dense chemotherapy in breast cancer patients with high risk of relapse has been confirmed and was implemented in national [18] and international guidelines [19].

Data regarding the long-term efficacy of dose-dense chemotherapy on the patient level is rare. The long-term follow-up data after 10 years of the dose-dense and dose-intense AGO-ETC study (AGO = Arbeitsgemeinschaft Gynäkologische Onkologie; Working Group Gynaecological Oncology) were presented, showing a persistent advantage for the dose-dense, dose-intense approach with epirubicin/paclitaxel/cyclophosphamide (ETC) q2w, leading to a relapse-free survival (RFS) rate of $56 \%$ and an OS of $69 \%$ compared to EC-P q3w with an RFS of $47 \%$ and an OS of $59 \%$ for the whole cohort ( $\mathrm{p}=0.00014$, HR $0.74,95 \%$ CI $0.63-0.87 ; \mathrm{p}=0.0007$, HR 0.72, 95\% CI 0.60-0.87, respectively) [20]. The CALGB 9741 data presented after 12 years of follow-up support the long-term benefit of dose-dense chemotherapy [12].

Recently, the results of a meta-analysis from the Early Breast Cancer Trialists' Collaborative Group (EBCTCG) [21] on dosedense and dose-intense chemotherapy regimens were published, clearly demonstrating a significant reduction in breast cancer recurrence and death in patients receiving dose-dense chemotherapy (2- vs. 3-weekly application). The analysis was performed on 34,122 patients from 24 different trials with a median follow-up of 10 years. The advantage for the dose-dense chemotherapy was consistent in oestrogen receptor(ER)-positive and ER-negative pa- tients and applicable to further tumour characteristics. The final publication is pending.

The first publication of our study demonstrated a trend for improved DFS and OS for patients receiving epirubicin and paclitaxel every 2 weeks followed by CMF every 2 weeks compared to standard-dose EC followed by CMF every 3 weeks in patients with more than 3 positive lymph nodes. In a median follow-up after 38.4 months, a non-significant advantage was presented in favour of the dose-dense chemotherapy [22]. Here, we present long-term followup data of this dose-dense chemotherapy study on the patient level after a median follow-up of 12.3 years (range 10.1-17.4 years).

\section{Patients and Methods}

The study was an open-label, prospective, randomised, multicentre phase III trial. Details of the study have been reported previously [22]. Patients included into this trial had primary resected, histologically confirmed invasive breast cancer, with more than 3 positive axillary lymph nodes ( $\geq$ pN2a), pT1pT4 and no evidence of distant metastases. Surgical procedures, performed up to 15 days before randomisation, included $\mathrm{R} 0$ resection and axillary dissection levels I-II obligatory and level III depending on the clinical situation. Patients needed to have an Eastern Cooperative Oncology Group (ECOG) performance status of $0-2$, adequate organ function and no previous chemotherapy or radiotherapy.

Briefly, between July 1996 and December 2000, a total of 231 patients from 30 German centres were randomised to receive either 4 cycles of dose-dense epirubicin $\left(\mathrm{E}, 90 \mathrm{mg} / \mathrm{m}^{2}\right)$ and paclitaxel $\left(\mathrm{P}, 175 \mathrm{mg} / \mathrm{m}^{2}\right) \mathrm{q} 2 \mathrm{w}$ followed by 3 cycles of cyclophosphamide $600 \mathrm{mg} / \mathrm{m}^{2}$, methotrexate $40 \mathrm{mg} / \mathrm{m}^{2}$ and 5-fluorouracil $600 \mathrm{mg} / \mathrm{m}^{2}$ (CMF 600/40/600) by intravenous (i.v.) infusion $\mathrm{q} 2 \mathrm{w}$ (arm A) or 4 cycles of standard-dose $\mathrm{E}\left(90 \mathrm{mg} / \mathrm{m}^{2}\right)$ and cyclophosphamide $\left(600 \mathrm{mg} / \mathrm{m}^{2}\right) \mathrm{q} 3 \mathrm{w}$ followed by 3 cycles of CMF (600/40/600) q3w (arm B). Patients in arm A received primary prophylactic granulocyte colony-stimulating factor (G-CSF) therapy with filgrastim $(5 \mathrm{mg} / \mathrm{kg}$ /day beginning on day 5 and continuing until either day 13 or leucocyte counts reached $\left.4 \times 10^{9} / 1\right)$. Patients in arm $B$ received filgrastim if clinically indicated as secondary prophylaxis. The initial publication on efficacy and safety [22] after a median follow-up of 38.4 months included 216 patients as patients with a T4 tumour $(n=10)$ were excluded from analysis. In contrast to that publication, we here also included patients with a T4 tumour and therefore 226 patients were included in our analysis.

Safety and toxicity parameters of the patients were reported elsewhere [22, 23 ] and an update of the safety and toxicity data was not part of this analysis. Briefly, the tolerabilities and toxicities of the given chemotherapy regimens were similar between the treatment arms as the rates of early discontinuation, interruption of therapy and adverse events were comparable between the treatment arms. 1 patient died during therapy in arm B, none in arm A. All patients with positive ER or progesterone receptor (PR) status received tamoxifen 20 $\mathrm{mg} /$ day for 5 years. All patients who had undergone breast-conserving surgery received adjuvant radiotherapy (40-50 Gy) on completion of the chemotherapy. Determination of the human epidermal growth factor receptor 2 (HER2) status was not part of the routine diagnostics; therefore, we do not have information on this subgroup. None of the patients received an anti-HER2 therapy as adjuvant treatment. Local ethics committees of all participating sides approved the study. Informed consent was obtained from all individual participants included in the study.

\section{Statistical Analysis}

Statistical analysis was performed by using IBM SPSS Statistics version 23.0. A per-protocol analysis was performed. Differences in clinico-pathological variables according to the therapy arm were analysed by using Pearson's chi-square $\left(\chi^{2}\right)$ test. Fisher's exact test was used to compare the frequency distributions of 


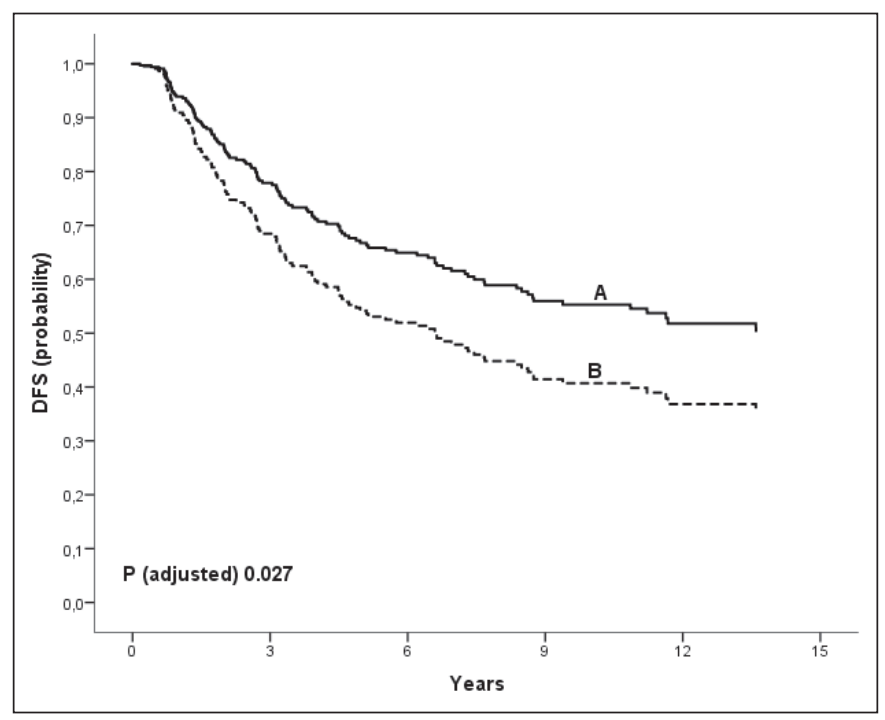

Fig. 1. Adjusted survival probability from multivariable Cox regression analysis for disease-free survival after a median follow-up of 12.3 years.

categorical variables while Student's t-test was used to compare the mean values for continuous variables between the therapy arms. Adjusted survival probability was analysed with multivariate Cox regression. Univariate and multivariate analyses were performed by using the Cox proportional hazards analysis to identify risk factors affecting RFS and OS after surgery. The factors included in the model were age, therapy arm (adjuvant chemotherapy), pT stage, lymph node status, lymphangiosis carcinomatosa, mode of surgery, and hormone receptor status. HRs including 95\% CIs were calculated. For all analyses, 2 -sided $\mathrm{p}$ $<0.05$ was considered statistically significant. The age cut-off is defined with the most significant (log-rank test) split.

\section{Results}

\section{Patient Characteristics}

In this per-protocol analysis, 226 patients were included: 113 patients in arm A and 113 patients in arm B. The baseline characteristics were well balanced between the treatment arms. Details of the baseline characteristics are shown in table 1. The median age was 55 years (range 25-71 years) at study entry. In the analysed cohort, patients had a median of 6 positive axillary lymph nodes (3-59). The majority had a T2 (50.4\%) and a hormone receptorpositive breast cancer disease (79.2\%). There is no information on the HER2 status of the included patients as the study was performed before the HER2 era.

\section{Outcome Analyses}

The median follow-up of the total cohort was 12.3 years (range 10.1-17.4 years). $25 \%$ of the cohort had a follow-up of 17 years, and $75 \%$, of at least 10 years.

After the median of 12.3 years follow-up, the DFS rate was $47.8 \%$ for the whole cohort and $53.1 \%$ in arm A and $42.5 \%$ in arm B. After 10 and 5 years, this was 53\% and 63\% in arm A and $43 \%$ and $55 \%$ in arm $B$, respectively ( $p=0.096$ ). The OS was $54.9 \%$ after 12.3 years, $61 \%$ and $91 \%$ after 10 and 5 years in arm $A$ and $48.7 \%$, $55 \%$ and $84 \%$ in arm $B$, respectively $(p=0.264)$.
Table 1. Baseline characteristics of the total study cohort

\begin{tabular}{|c|c|c|c|}
\hline Variables & $\begin{array}{l}\text { Arm A, } \\
\mathrm{n}(\%)^{\mathrm{a}}\end{array}$ & $\begin{array}{l}\text { Arm B, } \\
\mathrm{n}(\%)^{\mathrm{b}}\end{array}$ & $\mathrm{p}$ \\
\hline Number, $\mathrm{n}$ & 113 & 113 & \\
\hline Age, years & & & 0.875 \\
\hline Median (range) & $55(25-71)$ & $55(32-71)$ & \\
\hline Menopausal status & & & 0.892 \\
\hline Premenopausal & $44(38.9)$ & $45(39.8)$ & \\
\hline Postmenopausal & $69(61.1)$ & $68(60.2)$ & \\
\hline Laterality & & & 0.287 \\
\hline Left & $63(55.8)$ & $55(48.7)$ & \\
\hline Right & $50(44.2)$ & $58(51.3)$ & \\
\hline Type of local surgery & & & 0.684 \\
\hline Breast-conserving therapy & $44(38.9)$ & $47(41.6)$ & \\
\hline Mastectomy & $69(61.1)$ & $66(58.4)$ & \\
\hline pT & & & 0.799 \\
\hline 1 & $33(29.2)$ & $28(24.8)$ & \\
\hline 2 & $55(48.7)$ & $60(53.1)$ & \\
\hline 3 & $20(17.7)$ & $19(16.8)$ & \\
\hline 4 & $5(4.4)$ & $5(4.4)$ & \\
\hline $\mathrm{x}$ & 0 & $1(0.9)$ & \\
\hline $\begin{array}{l}\text { Number of involved metastatic } \\
\text { lymph nodes }\end{array}$ & & & 0.776 \\
\hline Median (range) & $6(4-28)$ & $6(4-59)$ & \\
\hline $4-9$ & $83(73.5)$ & $88(77.9)$ & 0.438 \\
\hline$>9$ & $30(26.5)$ & $25(22.1)$ & \\
\hline Lymphangiosis & & & 0.372 \\
\hline Negative & $49(43.4)$ & $59(52.2)$ & \\
\hline Positive & $50(44.2)$ & $44(38.9)$ & \\
\hline Unknown & $14(12.4)$ & $10(8.8)$ & \\
\hline Hormone receptor & & & 0.251 \\
\hline Negative & $27(23.9)$ & $20(17.7)$ & \\
\hline Positive & $86(76.1)$ & $93(82.3)$ & \\
\hline
\end{tabular}

${ }^{a}$ Arm A: dose-dense chemotherapy with EP-CMF q2w.

${ }^{b}$ Arm B: standard schedule chemotherapy with EC-CMF q3w.

EP-CMF $=$ Epirubicin/paclitaxel-cyclophosphamide/methotrexate/

5-fluorouracil; EC-CMF = epirubicin/cyclophosphamide-cyclophosphamide/ methotrexate/5-fluorouracil; q2w = every 2 weeks; $\mathrm{q} 3 \mathrm{w}=$ every 3 weeks.

The adjusted DFS and OS rates after a median of 12.3 years are shown in figure 1 and figure 2. The application of a dose-dense regimen led to a significant improvement of the DFS $(p=0.027)$ and to a marginal improvement of the OS ( $\mathrm{p}=0.058)$.

Further, we analysed the patient survival in clinically different subgroups. We did not find any statistically significant differences between the treatment arms with regard to hormone receptor status (positive vs. negative) and menopausal status (premenopausal vs. postmenopausal). The only optimal cut-off for the patient age was 43 years, with the younger patients having a significantly worse DFS ( $p=0.002)$ and OS $(p=0.001)$ in the log-rank analysis. The prognostic factors for DFS and OS in the univariate analysis were tumour size (stage 1 vs. later stages) and the amount of lymph node invasion (4-9 vs. $>9$ positive axillary lymph nodes). 
Table 2. Significance of tumour size for DFS and OS

\begin{tabular}{|c|c|c|c|c|c|c|c|c|}
\hline \multirow[t]{3}{*}{ Variables } & \multicolumn{4}{|l|}{ OS } & \multicolumn{4}{|l|}{ DFS } \\
\hline & \multicolumn{2}{|c|}{ Univariate analysis } & \multicolumn{2}{|c|}{ Multivariate analysis } & \multicolumn{2}{|c|}{ Univariate analysis } & \multicolumn{2}{|c|}{ Multivariate analysis } \\
\hline & HR (CI 95\%) & $\mathrm{p}$ & HR (CI 95\%) & $\mathrm{p}$ & HR (CI 95\%) & $\mathrm{p}$ & HR (CI 95\%) & $\mathrm{p}$ \\
\hline \multicolumn{9}{|l|}{ Age (cut at 43 years) ${ }^{\mathrm{a}}$} \\
\hline$>43$ years & 1 (ref.) & & 1 (ref.) & & 1 (ref.) & & 1 (ref.) & \\
\hline$\leq 43$ years & $1.81(1.11-2.89)$ & 0.013 & $2.19(1.34-3.59)$ & 0.002 & $1.42(0.70-2.92)$ & 0.335 & $1.63(0.77-3.42)$ & 0.200 \\
\hline \multicolumn{9}{|l|}{$\mathrm{pT}$} \\
\hline 1 & 1 (ref.) & & 1 (ref.) & & 1 (ref.) & & 1 (ref.) & \\
\hline 2 & $1.75(1.05-2.91)$ & 0.032 & $1.71(1.02-2.87)$ & 0.044 & $1.75(1.05-2.91)$ & 0.032 & $2.14(1.01-4.56)$ & 0.049 \\
\hline 3 & $2.31(1.26-4.24)$ & 0.007 & $2.31(1.26-4.24)$ & 0.002 & $2.31(1.26-4.24)$ & 0.007 & $2.72(1.01-7.36)$ & 0.048 \\
\hline $4 / \mathrm{X}$ & $4.57(2.12-9.82)$ & $<0.001$ & $4.57(2.12-9.82)$ & $<0.001$ & $4.57(2.12-9.82)$ & $<0.001$ & $10.6(3.3-34)$ & $<0.001$ \\
\hline \multicolumn{9}{|c|}{ Number of involved metastatic lymph nodes } \\
\hline 4-9 positive & 1 (ref.) & & 1 (ref.) & & 1 (ref.) & & 1 (ref.) & \\
\hline$>9$ positive & $1.54(1.03-2.32)$ & 0.037 & $1.39(0.89-2.18)$ & 0.176 & $1.54(1.03-2.32)$ & 0.037 & $0.75(0.37-1.54)$ & 0.435 \\
\hline \multicolumn{9}{|l|}{ Lymphangiosis } \\
\hline Negative & 1 (ref.) & & 1 (ref.) & & 1 (ref.) & & 1 (ref.) & \\
\hline Positive & $1.60(1.07-2.38)$ & 0.022 & $1.41(0.94-2.13)$ & 0.099 & $1.60(1.07-2.38)$ & 0.022 & $1.41(0.94-2.13)$ & 0.345 \\
\hline Unknown & $1.46(0.77-2.77)$ & 0.246 & $1.56(0.81-2.98)$ & 0.180 & $1.46(0.77-2.77)$ & 0.246 & $1.56(0.81-2.98)$ & 0.416 \\
\hline \multicolumn{9}{|l|}{ Hormone receptor } \\
\hline Positive & 1 (ref.) & & 1 (ref.) & & 1 (ref.) & & 1 (ref.) & \\
\hline Negative & $1.17(0.73-1.86)$ & 0.523 & $1.47(0.90-2.41)$ & 0.127 & $1.17(0.73-1.86)$ & 0.523 & $1.08(0.51-2.28)$ & 0.842 \\
\hline \multicolumn{9}{|l|}{ Type of local surgery } \\
\hline Mastectomy & 1 (ref.) & & 1 (ref.) & & 1 (ref.) & & 1 (ref.) & \\
\hline $\begin{array}{l}\text { Breast-conserving } \\
\text { therapy }\end{array}$ & $1.03(0.70-1.51)$ & 0.892 & $1.28(0.85-1.92)$ & 0.235 & $1.03(0.70-1.51)$ & 0.892 & $1.52(0.85-2.72)$ & 0.160 \\
\hline
\end{tabular}

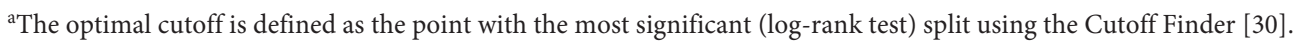

$\mathrm{OS}=$ Overall survival; DFS = disease-free survival; $\mathrm{HR}=$ hazard ratio; $\mathrm{CI}=$ confidence interval; ref. $=$ reference.

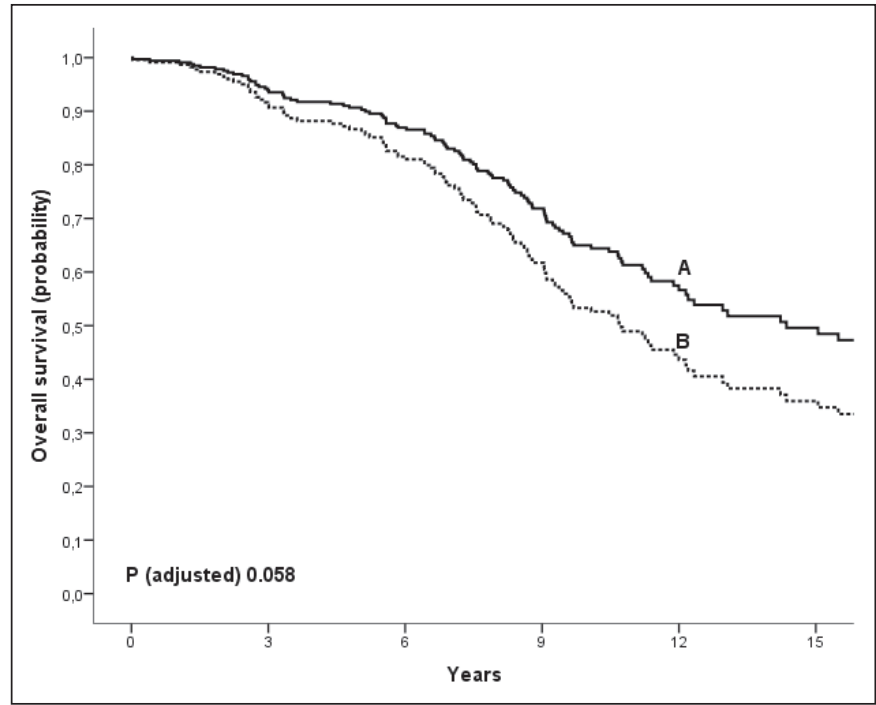

Fig. 2. Adjusted survival probability from multivariable Cox regression analysis for overall survival after a median follow-up of 12.3 years.

In the multivariable analysis, the tumour size remained significant for DFS and OS, and the lymph node status for DFS ( $p=0.012$ ). Details are summarised in table 2. Patients with higher tumour sizes had a significantly higher risk of positive lymph nodes $(p>0.001)$.

\section{Discussion}

After a median follow-up of 12.3 years, the use of dose-dense chemotherapy consisting of EP $\mathrm{q} 2 \mathrm{w}$ followed by CMF $\mathrm{q} 3 \mathrm{w}$ in breast cancer patients with more than 3 positive ipsilateral axillary lymph nodes led to a significantly better DFS compared to a standard-dose chemotherapy regime consisting of EC q3w followed by CMF q3w ( $\mathrm{p}=0.027)$. The adjusted analysis for OS showed a trend towards an improvement of OS in patients receiving the dosedense chemotherapy $(\mathrm{p}=0.058)$. In the subgroup analysis, patients with higher tumour burden due to greater tumour sizes and higher lymph node invasion had a significant benefit from the dose-dense chemotherapy application. The relative risk of recurrence was reduced by $34 \%$ in patients receiving dose-dense chemotherapy.

The published results after a median follow-up of 38.4 months showed a trend towards an improvement of DFS in patients receiving dose-dense chemotherapy (arm A), without statistical significance [22]. The steady increase of recurrence and death from breast cancer, irrespective of lymph node invasion, has been described impressively by Pan et al. [24]. In their meta-analysis on 62,923 patients from 88 trials, patients with ER-positive breast cancer and with more than 3 positive axillary lymph nodes had a risk of recurrence of $36 \%$, and the risk of dying was $29 \%$ after 10 years. 
Therefore, the OS rate of $58 \%$ of the whole cohort of our analysis is comparable, especially when taking into account that $24 \%$ had more than 9 positive lymph nodes.

In recent years, the knowledge about dose-dense chemotherapy and its optimal sequence, dosing and combinations has increased. When the studies on dose-dense/dose-intensified therapy were designed, they varied in regard to their schedule, sequences and dose density. There was the option of shortening the intervals (dose dense: every 2 weeks instead of every 3 weeks) and/or increasing their dosing (dose dense and dose intensified) [14, 16, 25]. The published studies are not always homogeneous regarding the way of increasing the dose (dose dense vs. dose intensified) and therefore it is not always possible to clearly separate those approaches. Nevertheless, the recently published meta-analysis by the EBCTCG [21] clearly underlines the advantage of dose-dense and dose-intensified regimens after analysing individual patient data from 25 trials including over 34,000 patients.

After a median follow-up of 3 years, the standard-dose arm of the TECHNO trial [4] with epirubicin $\left(90 \mathrm{mg} / \mathrm{m}^{2}\right)$ followed by paclitaxel $\left(175 \mathrm{mg} / \mathrm{m}^{2}\right) \mathrm{q} 3 \mathrm{w}$ followed by CMF $\mathrm{q} 3 \mathrm{w}$ showed similar DFS and OS results to the dose-dense arm of our study after a median follow-up of 38.5 months. The Hellenic Cooperative Oncology Group HE 10/00 phase II trial [8] investigated comparable regimens as adjuvant treatment for node-positive breast cancer. After a median follow-up of 5 years, the DFS ( $74 \%$ for both arms) and OS rates $(86 \%$ for the dose-dense arm vs. $85 \%$ for the standard-dose arm) in patients receiving either dose-dense $\mathrm{E}(110)-\mathrm{P}(250) \mathrm{q} 2 \mathrm{w}-$ CMF q2w or standard-dose $\mathrm{E}(83)-\mathrm{P}(187) \mathrm{q} 3 \mathrm{w}-\mathrm{CMF} \mathrm{q} 2 \mathrm{w}$ were comparable. Despite comparable OS rates to our analysis after 5 years, the DFS rates of our analysis were worse with $63 \%$ and $55 \%$ in the dose-dense and standard-dose arm, respectively. The differences might be due to differences in the lymph node status $[4,8]$.

The outstanding aspect of our study is the long-term follow-up. The studies mentioned above have only published data after follow-up periods of 3-5 years. The AGO-ETC study $[5,20]$ presented comparable dose-dense long-term follow-up data of at least 10 years. The AGO-ETC trial used an anthracyclines/taxane(AT)based combination chemotherapy regimen with dose-dense and dose-intense $3 \times \mathrm{E}(150) / \mathrm{P}(225) / \mathrm{C}(2500) \mathrm{q} 2 \mathrm{w}$ versus the standard regime $4 \times \mathrm{EC}(90 / 600) \mathrm{q} 3 \mathrm{w}-4 \times \mathrm{P}(175) \mathrm{q} 3 \mathrm{w}$. First long-term data were presented at the San Antonio Breast Cancer Symposium (SABCS) 2012, with a time-to-relapse rate after a median follow-up of 10 years of $56 \%$ versus $47 \%$ for dose-dense versus standard-dose therapy ( $\mathrm{p}=0.00014)$ and OS rates of $69 \%$ versus $59 \%$, respectively $(\mathrm{p}=0.0007)$. With this, the OS of the standard AT-based regimens is comparable to the OS of our dose-dense AT-based arm with an OS of $61 \%$ after 10 years of follow-up. The significant benefit of the dose-dense arm over the standard-dose arm of the AGO-ETC trial was mainly driven by the patients with more than 9 positive lymph nodes ( $\mathrm{p}=0.0016$; HR $0.66,95 \%$ CI $0.51-0.86$ ). The OS for patients with 4-9 positive lymph nodes was not statistically significant $(\mathrm{p}=$ 0.061, two-sided; HR 0.77, 95\% CI 0.59-1.01). In the ETC-AGO trial, the underlying subgroup did not significantly influence the impact of dose-dense chemotherapy as both hormone receptor- positive and HER2-positive patients benefitted from the dosedense approach. Therefore, our data are concordant to the AGOETC trial, with both studies demonstrating the highest benefit for the patients with high tumour burden.

Adding anthracyclines to a CMF-containing chemotherapy led to an improved outcome in early breast cancer [26]. This benefit was further improved by giving AT-containing combination chemotherapy in node-positive breast cancer versus taxane-free combination chemotherapies $[15,27]$.

There are limitations to our analysis needing be discussed openly. Due to the nature of our analysis with a median follow-up period of 12.3 years, the information regarding the patients' outcome has the risk of being biased. We have considered this and presented only reliable and reproducible data as we focused on the DFS and OS analysis.

Because the study was conducted before the HER2 era, we do not have information on the HER2 overexpression in the patients of our cohort and cannot rule out that this has an influence on the results. Finally, despite being a phase III trial, the study might be underpowered to be able to show a significant benefit for the dosedense chemotherapy arm as we only included 231 patients in total, with 226 patients being analysed. We also need to consider that the used regimens are no longer standard of care in patients with breast cancer. National and international guidelines recommend using AT-containing regimes as favoured treatment options. The addition of CMF to an anthracycline-containing regime induces more toxicity, without improving the efficacy, and is therefore considered obsolete.

Another interesting aspect is the rate of secondary malignancies, which we cannot address in our analysis. According to the literature, the risk for acute myeloid leukaemia (AML) or myelodysplastic syndrome (MDS) varied between $0.5 \%$ after a median follow-up of 3 years to $1.3 \%$ after a follow-up period of 10 years [ 13 , $22,28,29]$ in patients receiving dose-dense anthracycline-containing chemotherapy. The EBCTCG meta-analysis [21] also demonstrated reduced all-cause mortality in patients receiving dose-dense chemotherapy; therefore, the rate of secondary malignancy does not seem to have an impact on the overall benefit of the dose-dense chemotherapy approach.

Summarising the results, we were able to demonstrate that the biweekly given AT-based dose-dense regimes led to an improved DFS, especially in patients with more than 9 positive lymph nodes and higher tumour burden compared to the 3-weekly anthracycline- and cyclophosphamide-based chemotherapy.

There are more phase III studies investigating the benefit of dose-dense chemotherapy regimens. But since the EBCTCG metaanalysis [21] has been presented, the benefit of a dose-dense chemotherapy approach is unquestionable, though the final results of the full publication is pending and is eagerly awaited.

\section{Disclosure Statement}

The updated follow-up analysis was done without additional funding. All authors declare no competing interest. 


\section{References}

1 Early Breast Cancer Trialists' Collaborative Group (EBCTCG); Peto R, Davies C, Godwin J, et al: Comparisons between different polychemotherapy regimens for early breast cancer: meta-analyses of longterm outcome among 100000 women in 123 randomised trials. Lancet 2012;379:432-444.

2 Early Breast Cancer Trialists' Collaborative Group (EBCTCG); Clarke M, Coates AS, Darby SC, et al: Adjuvant chemotherapy in oestrogen-receptor-poor breast cancer: patient-level meta-analysis of randomised trials. Lancet 2008;371:29-40.

$\checkmark 3$ Citron ML, Berry DA, Cirrincione C, et al: Randomized trial of dose-dense versus conventionally scheduled and sequential versus concurrent combination chemotherapy as postoperative adjuvant treatment of node-positive primary breast cancer: first report of Intergroup Trial C9741/Cancer and Leukemia Group B Trial 9741. J Clin Oncol 2003;21:1431-1439.

$\checkmark 4$ Untch M, Möbus V, Kuhn W, et al: Intensive dosedense compared with conventionally scheduled preoperative chemotherapy for high-risk primary breast cancer. J Clin Oncol 2009;27:2938-2945.

5 Moebus V, Jackisch C, Lueck H-J, et al: Intense dosedense sequential chemotherapy with epirubicin, paclitaxel, and cyclophosphamide compared with conventionally scheduled chemotherapy in high-risk primary breast cancer: mature results of an AGO phase III study. J Clin Oncol 2010;28:2874-2880.

6 Del Mastro L, De Placido S, Bruzzi P, et al: Fluorouracil and dose-dense chemotherapy in adjuvant treatment of patients with early-stage breast cancer: an open-label, $2 \times 2$ factorial, randomised phase 3 trial. Lancet 2015;385:1863-1872.

7 Wood WC, Budman DR, Korzun AH, et al: Dose and dose intensity of adjuvant chemotherapy for stage II, node-positive breast carcinoma. N Engl J Med 1994; 330:1253-1259.

8 Gogas H, Dafni U, Karina M, et al: Postoperative dosedense sequential versus concomitant administration of epirubicin and paclitaxel in patients with node-positive breast cancer: 5-year results of the Hellenic Cooperative Oncology Group HE 10/00 phase III trial. Breast Cancer Res Treat 2012;132:609-619.

9 Foukakis T, von Minckwitz G, Bengtsson N-O, et al Effect of tailored dose-dense chemotherapy vs standard 3-weekly adjuvant chemotherapy on recurrencefree survival among women with high-risk early breast cancer: a randomized clinical trial. JAMA 2016;316: 1888-1896.
Levine MN, Pritchard KI, Bramwell VHC, et al: Randomized trial comparing cyclophosphamide, epirubicin, and fluorouracil with cyclophosphamide, methotrexate, and fluorouracil in premenopausal women with node-positive breast cancer: update of National Cancer Institute of Canada Clinical Trials Group Trial MA5. J Clin Oncol 2005;23:5166-5170.

11 Venturini M, Del Mastro L, Aitini E, et al: Dose-dense adjuvant chemotherapy in early breast cancer patients: results from a randomized trial. J Natl Cancer Inst 2005;97:1724-1733.

12 Liu MC, Pitcher BN, Mardis ER, et al: PAM50 gene signatures and breast cancer prognosis with adjuvant anthracycline- and taxane-based chemotherapy: correlative analysis of C9741 (Alliance). NPJ Breast Cancer 2016;2:pii 15023.

13 Cameron D, Morden JP, Canney P, et al: Accelerated versus standard epirubicin followed by cyclophosphamide, methotrexate, and fluorouracil or capecitabine as adjuvant therapy for breast cancer in the randomised UK TACT2 trial (CRUK/05/19): a multicentre, phase 3, open-label, randomised, controlled trial. Lancet Oncol 2017;18:929-945.

14 Reinisch M, Ataseven B, Kümmel S: Neoadjuvant dose-dense and dose-intensified chemotherapy in breast cancer - review of the literature. Breast Care (Basel) 2016;11:13-20.

15 Bonilla L, Ben-Aharon I, Vidal L, Gafter-Gvili A, Lei bovici L, Stemmer SM: Dose-dense chemotherapy in nonmetastatic breast cancer: a systematic review and meta-analysis of randomized controlled trials. J Natl Cancer Inst 2010;102:1845-1854.

16 Möbus V: Adjuvant dose-dense chemotherapy in breast cancer: standard of care in high-risk patients. Breast Care 2016;11:8-12.

17 Petrelli F, Cabiddu M, Coinu A, et al: Adjuvant dosedense chemotherapy in breast cancer: a systematic review and meta-analysis of randomized trials. Breast Cancer Res Treat 2015;151:251-259.

18 www.ago-online.de/de/infothek-fuer-aerzte/leitlinienempfehlungen/mamma/.

19 NCCN: NCCN Guidelines ${ }^{\circledR}$. 2017. www.nccn.org/professionals/physician_gls/__guidelines.asp.

20 Moebus V, Jackisch C, Lueck HJ, et al: Ten-year follow-up analysis of intense dose-dense adjuvant ETC (epirubicin (E), paclitaxel (T) and cyclophosphamide (C)) confirms superior DFS and OS benefit in comparison to conventional dosed chemotherapy in highrisk breast cancer patients with $\geq 4$ positive lymph nodes. SABCS 2012;abstr S3-04.
21 Gray R, Bradley R, Braybrooke J, et al: Increasing the dose density of adjuvant chemotherapy by shortening intervals between courses or by sequential drug administration significantly reduces both disease recurrence and breast cancer mortality: an EBCTCG metaanalysis of 21,000 women in 16 randomised trials. SABCS 2017; abstr GS 1-01.

22 Kümmel S, Krocker J, Kohls A, et al: Randomised trial: survival benefit and safety of adjuvant dose-dense chemotherapy for node-positive breast cancer. Br J Cancer 2006;94:1237-1244.

23 Elling D, Krocker J, Kümmel S, et al: Dose intensified adjuvant chemotherapy in high risk breast carcinoma with 4-9 positive lymph nodes (Article in German). Zentralbl Gynakol 2000;122:207-216.

24 Pan H, Gray R, Braybrooke J, et al: 20-Year risks of breast-cancer recurrence after stopping endocrine therapy at 5 years. N Engl J Med 2017;377:1836-1846.

25 Kümmel S, Rezai M, Kimmig R, Schmid P: Dose-dense chemotherapy for primary breast cancer. Curr Opin Obstet Gynecol 2007;19:75-81.

26 Earl HM, Hiller L, Dunn JA, et al: Adjuvant epirubicin followed by cyclophosphamide, methotrexate and fluorouracil (CMF) vs CMF in early breast cancer: results with over 7 years median follow-up from the randomised phase III NEAT/BR9601 trials. Br J Cancer 2012;107:1257-1267.

27 Early Breast Cancer Trialists' Collaborative Group (EBCTCG): Effects of chemotherapy and hormonal therapy for early breast cancer on recurrence and 15 year survival: an overview of the randomised trials. Lancet 2005;365:1687-1717.

28 Muss HB, Berry DA, Cirrincione C, et al: Toxicity of older and younger patients treated with adjuvant chemotherapy for node-positive breast cancer: the Cancer and Leukemia Group B experience. J Clin Oncol 2007;25:3699-3704.

29 Freedman RA, Seisler DK, Foster JC, et al: Risk of acute myeloid leukemia and myelodysplastic syndrome among older women receiving anthracyclinebased adjuvant chemotherapy for breast cancer on Modern Cooperative Group trials (Alliance A151511). Breast Cancer Res Treat 2017;161:363-373.

30 Budczies J, Klauschen F, Sinn BV, et al: Cutoff Finder: a comprehensive and straightforward Web application enabling rapid biomarker cutoff optimization. PLoS One 2012;7:e51862. 